\title{
Fetal doppler predictor of neonatal coarctation of the aorta
}

\begin{abstract}
Objective: To describe fetal quantitative Doppler predictor of neonatal Coarctation of the aorta (CoAo).

Methods: We retrospectively selected all cases of prenatal CoAo suspicion between December 2012 and August 2014 at the Fetal Cardiology Unit, Ukrainian Children's Cardiac Center, Kyiv, Ukraine. Only fetuses with suspicion of isolated CoAo and complete follow-up were included in the study. Sixty six (66) cases were analyzed. Echocardiographic parameters obtained after 32 gestational weeks were compared in true and false-positive groups. Optimal cut-off for the isthmic-ductal diastolic flow indices difference (IDDFID) was identified and the corresponding likelihood ratios used to calculate the post-test probability of CoAo in each fetus.
\end{abstract}

Results: CoAo was confirmed in 44/66 cases (66.7\%). After 32 weeks of gestation cut-off value of the IDDFID was $\geq 0.2$. The mean post-test probabilities of CoAo were higher in fetuses with confirmed CoAo than in fetuses with false suspicion ( 85 vs $30 \%$; $\mathrm{P}<0.0001$ ).

Conclusion: We have described fetal quantitative Doppler criterion which is a step to objectivization of assessment of aortic isthmus flow disturbance and improvement of the accuracy of fetal echocardiography for prediction of neonatal CoAo.
Volume 2 Issue I - 2015

\author{
Oleksii Ostras \\ Fetal Cardiology Unit, Ukrainian Children?s Cardiac Center, \\ Ukraine
}

Correspondence: Oleksii Ostras, Fetal Cardiology Unit, Ukrainian Childrens Cardiac Center 28 / I Chornovola street, 0 I I 35 Kyiv, Ukraine, Tel 3809540 I I585, Fax 3804428403 I I, Email oostras@gmail.com

Received: January 02, 2015 | Published: January 06, 2015

Keywords: coarctation of the aorta, fetal echocardiography, doppler

Abbreviations: CoAo, coarctation of the aorta; 3VT, three vessels and trachea; DA, ductus arteriosus; VTI, velocity time integral; IDDFID, isthmic-ductal diastolic flow indices difference; CHD, congenital heart defect; ROC, receiver-operating characteristics; AUC, area under the curve; LR, likelihood ratio

\section{Introduction}

Coarctation of the aorta (CoAo) is one of the most common congenital heart defects (CHD), accounting for approximately $7 \%$ of all live births with CHD. ${ }^{1}$ This is the most common duct-dependent CHD missed at routine physical screening of the neonate. ${ }^{2}$ Correct prenatal diagnosis of CoAo improves survival and reduces morbidity by allowing planned delivery in an appropriate center and early prevention of ductal constriction. ${ }^{3}$ Currently prenatal diagnosis of this condition lacks sensitivity at screening and specificity even when performed by experts in tertiary centers. This leads to increased morbidity and mortality in affected neonates without correct prenatal diagnosis, who often collapse and require resuscitation before surgery $2,4,5$ and unjustified costs of cardiac centers due to false-positive cases ${ }^{6}$. Despite advances in fetal echocardiography and the description of antenatal findings associated with neonatal CoAo, this lesion remains the most challenging diagnosis to be made in fetal and early neonatal life. ${ }^{6-10}$ To the best of our knowledge quantitative fetal Doppler criteria of neonatal CoAo have not been described in the literature.

\section{Materials and methods}

\section{Prenatal data}

Retrospective study was performed at a tertiary care center (Ukrainian Children's Cardiac Center, Kyiv, Ukraine). All cases of prenatal suspicion of CoAo were selected from Fetal Cardiology Unit computerized database in the period from December 2012 till August 2014. Echocardiographic examinations were performed with a Philips iU22 machine (Philips Ultrasound, Bothell, WA) with C5-1 transabdominal transducer and recorded on digital storage. All analyzed prenatal information was obtained from examinations after 32 weeks of gestation. Gestational age was calculated from the last menstrual period, confirmed by first-trimester scan. The suspicion of fetal CoAo was based on aortic isthmus Z-score $<-2 \mathrm{SD}$, isthmus-toduct Z-score $<-2 \mathrm{SD}$ and right-to-left heart structures ratio more than 1.6. Fetuses with persistent left superior vena cava were included. The cases of combined major intracardiac anomalies, such as significant ventricular septal defect, subvalvar aortic stenosis were excluded. The study was approved by Center Ethics Committee.

Fetal ultrasound examinations included a detailed echocardiography. ${ }^{11}$ Cardiac dimensions were measured from inner edge to inner edge. The aortic isthmus dimension was measured immediately proximal to the insertion of the arterial duct in the three vessels and trachea (3VT) view. The ductal diameter was measured in the same view. ${ }^{8}$ The cardiac measurements were performed during echocardiography and appropriate Z-scores were calculated using existing equations. ${ }^{8,12}$ Disturbance of blood flow through aortic arch was subjectively assessed by using Color Doppler. Pulsed wave Doppler spectrograms in ductus arteriosus (DA) and aortic isthmus and pulmonary valve were recorded separately with an ultrasound angulation of $<30$ degrees. Analysis of these spectrograms was performed retrospectively by one observer who was unaware of the postnatal outcome. On pulmonary valve spectrogram ejection time was measured. This time interval was used for separation between systolic and diastolic waves either in DA and aortic isthmus. Systolic and diastolic velocity time integrals (VTI) were obtained on both DA and aortic isthmus spectrograms (Figure 1). An average of three consecutive measurements was analyzed. The diastolic flow index was calculated on both DA and aortic isthmus with the following equation: 


$$
\text { Diastolic flow index }=\frac{\text { diastolic VTI }}{(\text { systolic VTI }+ \text { diastolic VTI })}
$$

To mitigate various hemodynamic factors simultaneously affect the nature of blood flow through the aortic isthmus and DA, the difference between isthmic and ductal diastolic flow indices (IDDFID) was calculated.

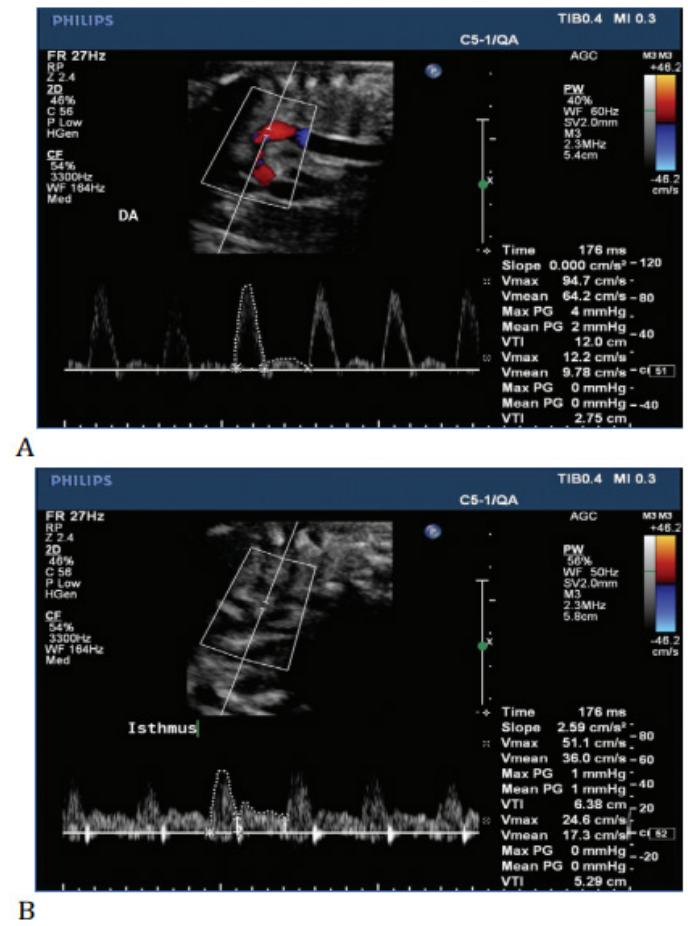

Figure I Doppler spectrograms in the ductus arteriosus (A) and aortic isthmus (B) with appropriate tracings in a 36-week fetus with coarctation of the aorta confirmed in neonate. The isthmic-ductal diastolic flow indices difference $=(5.29 /(6.38+5.29))-(2.75 /(12.0+2.75))=0.27$

\section{Postnatal data and outcomes}

In cases of perinatal death the information about presence or absence of CoAo was obtained from postmortem examinations. In accordance with the protocol of the Center live births patients who had prenatal suspicion of isolated CoAo with normal dimensions of mitral valve we evaluated not later than fifth day after birth (mean $3 \pm 1$ day). Patients in described series did not have signs of cardiac failure before postnatal evaluation. Neonates with confirmed CoAo was admitted and operated in stable status. In cases when patent DA precluded CoAo excluding, patients was admitted to cardiological division for clinical and echocardiographical monitoring without prostaglandin infusion. CoAo was confirmed or excluded after natural closure of DA. Exclusion criteria of CoAo were absence of blood pressure difference between right arm and leg and absence of echocardiographic data of aortic arch narrowing. For detection of late presentation of $\mathrm{CoAo}^{7}$ patients in whom CoAo was not confirmed underwent a cardiological and echocardiographycal follow-up at 1 and 3 months of age.

\section{Statistical Analysis}

\section{Two outcome groups were defined}

CoAo confirmation (postnatal and postmortem) and false-positives (postnatal and postmortem). Descriptive statistics were presented as mean \pm SD for continuous variables and as percentages for categorical variables. Differences in categorical variables were assessed by the chi-square or Fisher's exact test and continuous variables by Student's t-test or the Mann-Whitney U-test, where appropriate. P for all tests was two-sided and the criterion for statistical significance was $\mathrm{P}<0.05$. Receiver-operating characteristics (ROC) analysis was performed and the area under the curve (AUC) calculated for assessment of the sensitivity and specificity of the IDDFID for predicting outcome. The optimal cut-off point for this parameter was derived from ROC analysis and the corresponding likelihood ratios (LR) was calculated. The post-test probability of CoAo in each fetus was evaluated. All analyses were performed using SPSS19.0 (SPSS Inc., Chicago, IL, USA).

\section{Results and discussion}

During the study period the suspicion of CoAo was established in 75 fetuses. The majority of women $(n=53,70.7 \%)$ were referred for a detailed fetal echocardiography due to suspected CHD. The rest were attending because of family history of CHD. Nine (12.0\%) of the 75 fetuses were excluded from full analysis. There were no cases of prenatally missed neonatal CoAo during the study period. In 15 of 19 $(78.9 \%)$ cases of prenatal- and intranatal death CoAo was confirmed by postmortem examination. CoAo was confirmed postnatally in $34 / 53$ neonates $(64.2 \%)$ and was excluded in the remaining 19. Figure 2 summarizes the outcomes for the whole patients and the reasons for exclusion. The study population included 13 fetuses of prenatal loss subgroup who have echocardiographic examinations after 32 weeks of gestation and complete postmortem examination and 53 fetuses of live born subgroup with complete follow-up. General prenatal characteristics are summarized in (Table 1).

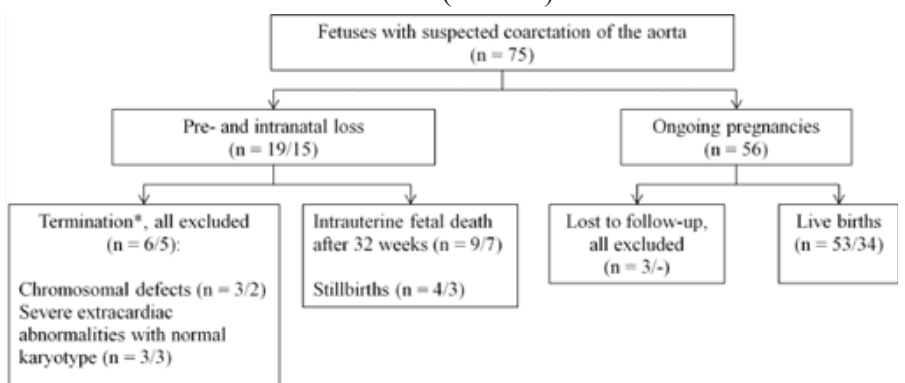

Figure 2 Circuit of fetuses with suspected coarctation of the aorta. *The upper limit for termination of pregnancy in Ukraine was 22 weeks. Data are given as number / including number of cases with confirmed coarctation of the aorta.

Table I General prenatal features of study population $(n=66)$

\begin{tabular}{ll}
\hline Feature & Value \\
\hline Gestational age at evaluation (weeks) & $34.3 \pm 1.7(32-40)$ \\
Singleton pregnancy & $63(95.5 \%)$ \\
Twin pregnancy & $3(4.5 \%)$ \\
Gestational age at birth (weeks) & $38.3 \pm 2.6(31-41)$ \\
Birth weight (g) & $2910 \pm 496(1640-3700)$ \\
\hline
\end{tabular}

Data given as $\mathrm{n}(\%)$ or mean $\pm \mathrm{SD}$ (range).

Most of the newborns with confirmed CoAo (33/34, 97.1\%) underwent CoAo repair at a mean age of $9.3 \pm 5.9$ days (median 7 (range, 1-31) days), and one newborn died before surgery at 3 days, owing to massive brain hemorrhage in settings of prematurity and cerebral arteriovenous malformation. Most of operated patients were alive and well at the time of writing $(32 / 34,97.1 \%)$ but one neonate died in the immediate postoperative period, secondary to undiagnosed complex intestine malformation. 


\section{Prenatal prediction}

The main findings at the fetal echocardiographic scan in outcome groups are shown in (Table 2). These groups had no significant difference in gestational age at evaluation. Fetuses with confirmed CoAo had significantly smaller Z-score for the aortic isthmus in the 3 VT view. The IDDFID was significantly larger in this group. There was not found differences between the outcome groups in presence of persistent left superior vena cava and subjectively assessed distorted aortic arch flow. Using the IDDFID as diagnostic test for neonatal CoAo, logistic regression analysis was performed. The cut-off value for this parameter was 0.2 , sensitivity $90.9 \%$, specificity $95.5 \%$, calculated positive LR 20.00, negative LR 0.095 . The ROC curve is shown in (Figure 3). Using the LRs, we estimated the post-test probability of CoAo, taking into account the pre-test odds for CoAo of $2.0(44 / 22)$ in study population.

Table 2 Prenatal ultrasound findings of the study population, according to outcome (postnatal or postmortem CoAo confirmation and false-positives, $\mathrm{n}=66)$

\begin{tabular}{|c|c|c|c|c|}
\hline Feature & $\begin{array}{l}\text { CoAo } \\
(n=44)\end{array}$ & $\begin{array}{l}\text { False- } \\
\text { positives } \\
(\mathrm{n}=22)\end{array}$ & $\begin{array}{l}\text { Difference } \\
\text { in means } \\
(95 \% \mathrm{Cl})\end{array}$ & $\mathbf{P}$ \\
\hline $\begin{array}{l}\text { Gestational age at } \\
\text { evaluation (weeks) }\end{array}$ & $34.5 \pm 1.7$ & $34.3 \pm 1.7$ & $\begin{array}{l}0.2(-1.1 \text { to } \\
1.5)\end{array}$ & $>0.1$ \\
\hline $\begin{array}{l}\text { Aortic isthmus (3VT } \\
\text { view) Z-score }\end{array}$ & $-3.6 \pm 0.8$ & $-2.6 \pm 0.4$ & $\begin{array}{l}-1.0(-1.5 \text { to } \\
-0.5)\end{array}$ & $<0.05$ \\
\hline $\begin{array}{l}\text { Difference between } \\
\text { isthmic and ductal } \\
\text { diastolic flow } \\
\text { indices }\end{array}$ & $0.26 \pm 0.5$ & $0.18 \pm 0.5$ & $\begin{array}{l}0.08(0.046 \\
\text { to } 0.12)\end{array}$ & $<0.001$ \\
\hline $\begin{array}{l}\text { Persistent left } \\
\text { superior vena cava }\end{array}$ & $4(8.2)$ & $3(13.0)$ & & $>0.1$ \\
\hline $\begin{array}{l}\text { Disturbance of } \\
\text { aortic arch blood } \\
\text { flow }\end{array}$ & $39(79.6)$ & I 8 (78.3) & & $>0.1$ \\
\hline
\end{tabular}

Data given as mean \pm SD or $n(\%)$. CoAo: coarctation of the aorta. 3VT: three vessels and trachea.

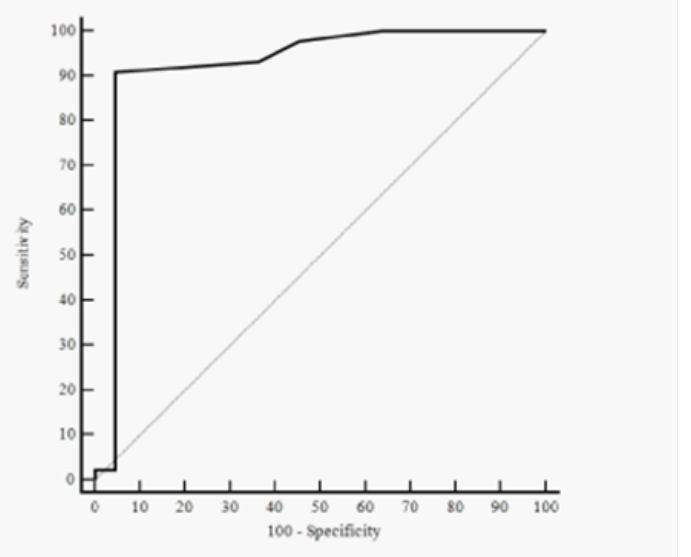

Figure 3 Receiver-operating characteristics (ROC) curve of the isthmicductal diastolic flow indices difference for prediction of neonatal coarctation of the aorta. Area under the ROC curve, 0.92 ( $95 \% \mathrm{Cl}, 0.83-0.98)$.

Prenatal diagnosis of CoAo remains a challenge. Arch obstruction occurs in the fetus; it is not a postnatal event but a dynamic situation in the fetus. ${ }^{9}$ Diagnostic accuracy may be improved by means of combining size-based cardiac parameters with gestational age at diagnosis. ${ }^{10}$ Flow disturbance at the isthmus is considered as one of the qualitative diagnostic features of CoAo in the fetuses. ${ }^{6,9,10}$ It is known description of flow disturbance as a delayed flow through aortic isthmus. At the same time the quantitative criteria of impaired aortic arch flow were not described earlier. We assumed that visualization of prolonged flow in the aortic isthmus associated with more expressed diastolic component. This can be explained by changes in resistance of the brachiocephalic vessels and actually narrowed isthmus. The nature of the isthmus flow influenced by the set of independent factors, such as placental and brachiocephalic vascular resistances, the volume of flow through it, its own size and others. Most of these factors are common for aortic isthmus and ductus arteriosus due to the morphological and functional proximity. To assess the diastolic component of flow in each vessel we used the ratio of appropriate diastolic and total VTI. To mitigate various hemodynamic factors simultaneously affect aortic isthmus and DA flow, we propose to calculate the difference between isthmic and ductal diastolic flow indices (IDDFID). The normal changes in the nature of aortic isthmus flow at different stages of prenatal development, feasibility and reliability of Doppler measurements have been described earlier. ${ }^{13,14}$

There are limitations in our study.

1. Its retrospective nature.

2. We assess the feasibility of using single Doppler parameter for diagnosing of isolated CoAo only after 32 weeks of gestation.

3. Our series included only fetuses with regular heart rhythm.

4. The validation of our results in future prospective studies will be necessary.

\section{Conclusion}

The IDDFID after 32 weeks of gestation is sensitive and specific parameter for prediction of neonatal CoAo. Using of such parameter may be the step to objectivization of assessment of aortic isthmus flow disturbance. The IDDFID could be incorporated as a part of multiparametric scoring system together with fetal morphological criteria of CoAo that needs further research.

\section{Acknowledgments}

None.

\section{Conflicts of interest}

Author declares there are no conflicts of interest.

\section{Funding}

None.

\section{References}

1. Rosenthal E. Coarctation of the aorta from fetus to adult: curable condition or life long disease process? Heart. 2005;91(11):1495-1502.

2. Chang RK, Gurvitz M, Rodriguez S. Missed diagnosis of critical congenital heart disease. Arch Pediatr Adolesc Med. 2008;162(10):969-974.

3. Franklin O, Burch $\mathrm{M}$, Manning $\mathrm{N}$, et al. Prenatal diagnosis of coarctation of the aorta improves survival and reduces morbidity. Heart. 2002;87(1):67-69.

4. Brown KL, Ridout DA, Hoskote A, et al. Delayed diagnosis of congenital heart disease worsens preoperative condition and outcome of surgery in neonates. Heart. 2006;92(9):1298-1302.

5. $\mathrm{Ng} \mathrm{B}$, Hokanson J. Missed congenital heart disease in neonates. Congenit Heart Dis. 2010;5(3):292-296. 
6. Jowett V, Aparicio P, Santhakumaran S, et al. Sonographic predictors of surgery in fetal coarctation of the aorta. Ultrasound Obstet Gynecol .2012;40(1):47-54

7. Head CEG, Jowett VC, Sharland GK, et al. Timing of presentation and postnatal outcome of infants suspected of having coarctation of the aorta during fetal life. Heart. 2005;91(8):1070-1074.

8. Pasquini L, Mellander M, Seale A, et al. Z-scores of the fetal aortic isthmus and duct: an aid to assessing arch hypoplasia. Ultrasound Obstet Gynecol. 2007;29(6):628-633.

9. Matsui H, Mellander M, Roughton M, et al. Morphological and Physiological Predictors of Fetal Aortic Coarctation. Circulation. 2008;118(18):1793-1801.

10. Gomez-Montes E, Herraiz I, Mendoza A, et al. Prediction of coarctation of the aorta in the second half of pregnancy. Ultrasound Obstet Gynecol. 2013;41(3):298-305.
11. Rychik J, Ayres N, Cuneo B, et al. American Society of Echocardiography guidelines and standards for performance of the fetal echocardiogram. $J$ Am Soc Echocardiogr. 2004;17(7):803-810.

12. Schneider C, McCrindle BW, Carvalho JS, et al. Development of Z-scores for fetal cardiac dimensions from echocardiography. Ultrasound Obstet Gynecol. 2005;26(6):599-605.

13. Fouron JC, Zarelli M, Drblik SP, et al. Flow Velocity Profile of the Fetal Aortic Isthmus Through Normal Gestation. Am J Cardiol . 1994;74(5):483-486.

14. Fouron JC, Siles A, Montanari L, et al. Feasibility and reliability of Doppler flow recordings in the fetal aortic isthmus: a multicenter evaluation. Ultrasound Obstet Gynecol. 2009;33(6):690-693. 